\title{
KNOWING WHICH APPS MANAGERS LIKE: A MANAGER APP PORTAL ACCOMMODATING THEIR USER PREFERENCES
}

\author{
Jorg H. Mayer, Markus Esswein, Reiner Quick and Sanjar Sayar \\ Darmstadt University of Technology \\ Hochschulstrasse 1, 64289 Darmstadt, Germany
}

\begin{abstract}
Nowadays, even apps for corporate management are respectable. Manager app portals complement such "run-a-business" apps with apps that make managers' business life easier. However, the right mix of apps makes the difference. Accommodating the user perspective, the objective of this article is to examine which apps disproportionately influence managers' perception of IS usefulness. Applying the Kano model and considering both "analyst-" and "consumer-type" managers, we employ findings from a manager focus group survey to discuss the strongest differentiators: (1) Offer collaboration bars and push notifications on changes to shared office documents for analyst managers. Get consumer managers "online" with news tickers. (2) Make core reports more interactive with drill downs and filters for manager self-service. (3) Take "fun and enjoyment" into account when accommodating managers' business life. (4) Consider that tablets create their own manager use case as a "first-stop information shop."
\end{abstract}

\section{KEYWORDS}

Apps for Managers, Kano Model, Information Systems (IS) Design for Use, IS Success, User-Group Preferences

\section{INTRODUCTION}

Mobility is still one of the most visible trends in Information Systems (IS) and companies expect mobile IS to make their workforce more efficient. Smartphones and tablets will be the first "go-to" device for more than $50 \%$ of all users (Gartner, 2018). Thanks to Apple's (Wired, 2010) million-dollar slogan “There's an app for that" and SAP's (SAP, 2019) FIORI tiles even apps for corporate management have been established. However, finance content alone is not sufficient to convince managers to go mobile. One of the managers we interviewed outlined, "I will not use an iPad just to have my financials electronically." Thus, the right mix of both "run-a-business" apps and those that make managers' business life easier are crucial to make the difference.

Understanding the perception of IS usefulness is particularly important in the field of management support, where strong idiosyncrasies must be considered. Managers tend to have higher expectations with respect to IS accommodating their user preferences (Volonino et al., 1995). Therefore, IS research must broaden its scope beyond pure deployment to include managers' IS use and impact perspective (Kettinger \& Marchand, 2011).

We define manager app portals as a combination of apps that conform to a model based on a standard (Heinemann \& Council, 2001). According Shneiderman's (1997) mantra “overview first, zoom and filter, then details-on-demand," app portals have to provide both a personalized "first-stop information shop" and an easy-to-use navigation for detailed information. Such portals promise managers to make fact-driven decisions faster than before-especially when they are mobile (Ostrov, 2014).

Following the task-technology fit theory, Goodhue and Thompson (1995) describe IS success as the degree to which IS accommodate a user's tasks. User preferences describe differences in the way humans use IS. Based on existing manager user group preferences, we specify "IS fit" as the way different apps (small capsulated software components (Zigurs \& Buckland, 1998)) accommodate these preferences. User preferences result in requirements with respect to how IS should provide functions. 
Based on Shneiderman (1997), Al-Kassab et al. (2014) examine the impact of visualization and analytics on managerial decision-making. However, an app portal accommodating managers' user perspective is currently not covered in literature. Thus, the objective of this article is to examine which apps disproportionately influence managers ' perception of IS usefulness. We consider managers as either "analysts" (those who primarily work more interactively with IS) or "consumers" (those who primarily consume IS information).

We motivate this article in terms of closing gaps in managers' perception of IS usefulness through a manager app portal. Based on the state of the art (literature review), we apply the Kano model (research model). With findings from a manager focus group, we come up with the strongest differentiators for successfully implementing manager app portals (results). We then discuss our results in manager interviews and present a prototype (synthesis). We end with a summary and avenues for future research.

\section{LITERATURE REVIEW}

By conducting a journal search, we focused on leading IS research outcomes provided by the London School of Economics ${ }^{1}$ (Wilcocks et al., 2008) and complemented them with journals from Human-Computer Interaction, computer science, and systems and software engineering. We added proceedings from ICIS, ECIS, AMCIS, and HICSS and accessed the journals via EBSCOhost, ScienceDirect, Google Scholar, and AIS Electronic Library. Table 1 informs about our Boolean search string.

Our search on titles and abstracts resulted in 461 hits, of which we found 32 to be relevant. We added user satisfaction and adoption as well as IS antecedents, determinants, and elements to our search string as they are associated with IS use (Benbasat \& Nault, 1990). A final back- and forward search led to 90 relevant publications, 23 of which deal with directly applicable requirements. We structured them regarding the elements of IS design theories employed as follows (Walls et al., 1992): (A) User model and effects of use (Zhang et al., 2002; Benbasat \& Nault, 1990); (B) Functional or non-functional user requirements (Sommerville, 2010); (C) Guidelines (March \& Smith, 1995).

Table 1. Boolean search string

\begin{tabular}{|l|l|l|l|l|l|l|}
\hline \multicolumn{2}{|c|}{} & \multicolumn{4}{|c|}{ OR } \\
\hline \multirow{2}{*}{\begin{tabular}{l} 
Apps \\
\multirow{2}{*}{$\begin{array}{l}\text { Cognitive } \\
\text { fit }\end{array}$}
\end{tabular}} & $\begin{array}{l}\text { Information } \\
\text { presentation }\end{array}$ & $\begin{array}{l}\text { User } \\
\text { preferences } \\
\text { and dialog control }\end{array}$ & $\begin{array}{l}\text { User require-ments, } \\
\text { attitudes, styles, } \\
\text { and processing }\end{array}$ & $\begin{array}{l}\text { Use cases, } \\
\text { design } \\
\text { guidelines }\end{array}$ & $\begin{array}{l}\text { User satis- } \\
\text { faction, } \\
\text { adoption }\end{array}$ & $\begin{array}{l}\text { IS antecedents, } \\
\text { determinants, elements } \\
\text { boards, cockpits }\end{array}$ \\
\hline
\end{tabular}

(A) User Model: A rigorous app clustering from managers' perspective is missing: With 34 publications, the state of the art of IS user models is comprehensive. 13 publications deal with cognitive styles and cover techniques for user-group analysis. According to Witkin et al. (1977), we examined two basic working styles among managers. Analyst managers seek causal relationships, prefer quantitative data, and pay attention to details (Huysmans, 1970). Consumer managers, in turn, pay less attention to details and rely on predefined content.

The remaining 21 publications cover effects of use by differentiating characteristics that impact IS design (age, gender, or expertise) or identifying groups of managers and their IS usage (Powell \& Jonson, 1995). Involving managers in IS design is more relevant than ever (Fteimi, 2017). Management Support Systems (MSS) have a five-decade tradition and represent a class of IS covering. Management Information Systems (MIS), Decision Support Systems (DSS), Executive Information Systems (EIS), and Knowledge Management Systems (KMS), and Business Intelligence (BI) for managers (Carlsson et al., 2009).

\footnotetext{
${ }^{1}$ This catalog incorporates not only mainstream IS journals, but also social studies. We chose the five top journals from each set, namely: MIS Quarterly, Information Systems Research, Information \& Management, Journal of Management Information Systems, and Decision Support Systems, as well as European Journal of Information Systems, Information \& Organization, Information Systems Journal, Journal of Organizational and End User Computing, and Journal of Information Technology.
} 
(B) Requirements analysis can be enhanced by considering "fun \& enjoyment:" Papageorgiou and De Bruyn (2010) identified monthly (financial) reporting as a key MSS capability. Associated analyses help managers to investigate details (Bergeron, 1995)., e.g. by applying filters or drill downs (Turban et al., 2013) or by creating own reports (Laudon \& Laudon, 2018). News ticker offer an overview so that managers do not have to collect the information from various sources. Neyem et al. (2012) emphasizes collaboration which offers asynchronous communication such as business emails (Lee-Partridge \& Snyder, 2012) and business calendars (Belkadi et al., 2013; Alvarado et al., 2011). Integrating an office suite is still uncommon in MSS (Watson \& Frolick, 2006; Lee \& Shim, 2006). Direct messages to colleagues are recognized. Herskovic et al. (2011) state that emails "at the push of a button" are important. Riemer et al. (2009) argue for shared office documents. Video conferencing offers synchronicity of face-to-face communication (Kim et al., 2018). Hess et al. (2014) include private email into the corporate environment.

Semi-business apps support managers' logistics when travelling (Kaneshige, 2011) and offer a search function. Wixom and Watson (2010) identify web browsers for pervasive MSS. Finally, we identified newspaper or business journal readers (Watson \& Frolick, 2006) and convenience apps such as restaurant finders or weather (Lee \& Shim, 2006). Thus, manager app portals should incorporate both constitutive apps for corporate management and complementing components, which may support managers' collaboration and new mobile business life requirements.

(C) Ready-to-use design guidelines are lacking: The publications we reviewed provide both lists of apps without a rigorous basis for their selection and attributes of single apps. Two articles consider managers' IS use situations and apps. We only found one method for clustering MSS user interface apps to examine which ones influence managers' user satisfaction. These findings focus on layouts for desktop PCs (Wu et al., 2011). We define mobile MSS as IS offering services for managers while they move from place to place, especially outside their workplace, where technology is accessible, but not necessarily embedded in the environment.

\section{RESEARCH MODEL}

The Kano model is an adequate approach to identify attractive quality attributes from a "customer" perspective (Chen et al., 2011), e.g., to differentiate between motivators that increase workspace satisfaction and hygiene factors that cause dissatisfaction when absent (Herzberg et al., 1959). The model is widely applied in several industry sectors and business objectives (Luor et al., 2015) mainly because it is appropriate to systematically accommodate managers' user preferences in a detailed manner. Compared to other methods for determining desired product attributes, e.g. preference regression or a conjoint analysis, the Kano model is less fatiguing for respondents. Thus, the Kano model enables researchers to focus systematically on managers' perception of IS usefulness. We follow a two-step approach to reach diverse results. First, we examine the user acceptance and experience. Second, we obtain data from both analyst and consumer managers of several companies.

\subsection{Examine Managers' Perception of IS Usefulness}

We transferred the Kano model to a model of understanding IS designs (Figure 1) and differentiate five categories of apps as follows (Matzler \& Hinterhuber, 1998):

1. Attractive apps ("A") disproportionately influence managers' satisfaction and function as the strongest

differentiator in design. Since managers do not expect IS to include these apps, the app's implementation and offering the features increase managers' enthusiasm.

2. One-dimensional apps ("O") result in satisfaction when present and in dissatisfaction when absent. Their presence impacts IS performance regarding a linear (one-dimensional) relation. Considering "the more, the better", managers' user satisfaction increases while the apps improve.

3. Must-be apps ("M") are taken for granted. Their absence strongly dissatisfies managers. However, these basic apps do not have the power to shift managers' user satisfaction beyond a neutral state.

4. Apps that managers do not care about are assigned into the indifferent ("I") category.

5. For apps in the reverse category ("R") a high degree of achievement results in dissatisfaction. Users who like easy-to-use IS handling might perceive the presence of too many app features as reverse quality. 
Figure 1 illustrates how these five categories of apps are classified by means of a Kano questionnaire containing a pair of questions for each app. The left side of Figure 1 shows both the first question determining managers' response to an app portal with a proposed app (functional question), and the second question concerning their response to the same portal without this app (dysfunctional question). Here, managers can answer as follows: (1) I dislike the app, meaning I will not use it. (2) I can live with it, meaning I do not like this app, (3) I am neutral. (4) It must be that way, meaning this app is essential and every manager should have it. (5) I like it that way very much, meaning it is a great and unexpected differentiator: The right side of Figure 1 demonstrates the apps' classification in one of the five Kano clusters.

Based on our state of the art, we arrived at 30 apps for the portal design. We structured them in three groups: (1) Besides the constitutive apps of supporting managers' corporate management task, we complement the portal design with apps (2) for manager collaboration, and (3) for mobile business life.

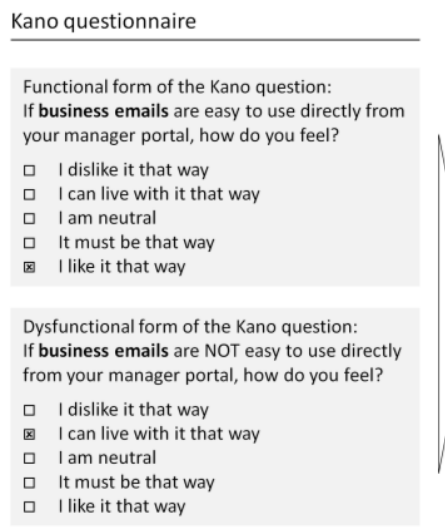

\begin{tabular}{|c|c|c|c|c|c|}
\hline $\begin{array}{l}\text { Dysfunctional form } \\
\text { of the question } \\
\text { Functional } \\
\text { form of the question }\end{array}$ & Dislike & Live with & Neutral & Must-be & Like \\
\hline Dislike & Q & $\mathrm{R}$ & $\mathrm{R}$ & $\mathrm{R}$ & $\mathrm{R}$ \\
\hline Live with & $M$ & 1 & 1 & 1 & $R$ \\
\hline Neutral & $M$ & 1 & 1 & 1 & $\mathrm{R}$ \\
\hline Must-be & M & 1 & 1 & 1 & $R$ \\
\hline Like & 0 & & A & A & Q \\
\hline
\end{tabular}

Legend: A: Attractive, O: One-dimensional, M: Must-be, I: Indifferent, R: Reverse, Q: Questionable

Figure 1. Kano model for IS design (Matzler \& Hinterhuber, 1998)

In order to find answers to the Kano questions, our manager focus group consisted of 25 Level 1 and Level 2 managers from eight companies (Table 2). Since 2006, they meet regularly three times a year to discuss trends in corporate management and IS support. The participants consisted of 16 analyst and 9 consumer managers. Taking into account that managers are difficult to attract for surveys, the total number of 25 can be considered as reasonable. Kano interviews were conducted in 30-minute face-to-face interviews. We calculated Cronbach's alpha (Cronbach, 1951) to determine the reliability of our results. Due to the scheme of the Kano questionnaire, the collected data was split and analyzed in two groups (functional and dysfunctional). Smartphones and tablets, as well as analyst and consumer managers were treated separately. With alpha values above 0.7 for both manager types and tablets, the results meet standard requirements for psychometric tests (analyst managers: 0.71 , consumer managers: 0.78$)$. The scores for smartphones $(0.58,0.55)$ are slightly below this threshold. Based on Cronbach (1951), higher values enhance interpretability but lower values do not necessarily prevent interpretability. Therefore, we did not discard the results for smartphones.

Table 2. Sample characteristics

\begin{tabular}{|c|c|c|c|c|c|}
\hline Position & No. & $\%$ & Sector & No. & $\%$ \\
\hline Executives (L1) & 11 & 44 & Industrial & 17 & 68 \\
\hline Director business dpt. (L2) & 6 & 24 & Financial services & 2 & 8 \\
\hline Frequency of IS use & No. & $\%$ & Working style & No. & $\%$ \\
\hline Permanent & 2 & 8 & Analyst & 16 & 64 \\
\hline 2-3 times/week & 6 & 24 & \multirow[t]{2}{*}{ Total } & \multirow[t]{2}{*}{25} & \\
\hline Once a week & 0 & 0 & & & \\
\hline
\end{tabular}




\subsection{Results}

We analyzed the results in four ways: First, all must-be apps ("M") were integrated in the manager app portal. Second, for the remaining apps, we calculated a coefficient to highlight most satisfying apps, the Extent of Satisfaction (EoS), with $E o S=\left(n_{A}+n_{O}\right) /\left(n_{A}+n_{O}+n_{M}+n_{I}\right)$. EoS can vary on a scale from 0.00 (no impact on satisfaction) to 1.00 (strong impact). We complement must-be apps by apps in our design with an EoS of 0.30 or more (Figure 2). We screened our results for apps with a high number of reverse evaluations, because EoS scores are calculated without taking reverse results into consideration. Fourth, we propose the use of an Extent of Dissatisfaction (EoD), which considers the most dissatisfying lacks of apps through $\mathrm{EoD}=\left(n_{M}+n_{O}\right) /\left(n_{A}+n_{O}+n_{M}+n_{I}\right)$.

Figure 3 presents a two-dimensional combination of EoS and EoD for all apps on the grid of the four Kano categories. The figure provides a classification of the apps as follows: Apps which several users consider a "must-be," a number consider attractive, and the remaining consider apps as indifferent and therefore do not receive the attention they should. They fall through the grid of the first must-be screening and get a relatively weak EoS score of around 0.3.

(1) Manager collaboration: Starting with the must-be apps on tablets and smartphones, analyst and consumer managers name business emails (app 1.1, numbering according to Figure 2, SC for software component) and business calendar (SC1.2.1). For analyst managers, annotations (SC 1.4.1.) are a must-be, whereas consumer managers consider them as satisfying $(0.56 ; 0.44)$. One-click collaboration (SC.1.4.3) is the app suited to increasing analyst managers' perception of IS usefulness most. It received an exceptional score on both tablets $(0.88)$ and smartphones $(0.56)$, whereas consumer managers are less interested $(0.33$ on both devices). Notifications on changes (SC1.5.2, 0.81; 0.63) in shared office documents (SC1.5.1, 0.63, 0.53) are also very attractive for analyst managers on both tablets and smartphones. Consumer managers are rather indifferent $(0.33,0.11)$. Finally, analyst managers ranked an office suite (SC1.3) as attractive (positioned almost in the center of Figure 3, left) on tablets (0.44), and less attractive on smartphones (0.36, positioned almost all the way to the left of Figure 3, right). Regarding apps that both manager types consider satisfying, high EoS scores were given to a news ticker (SC1.8) on smartphones $(0.69,0.71)$ and tablets $(0.69 ; 0.63)$. Video calling/conferencing (SC1.6) is attractive for both manager types on tablets and smartphones $(0.60 / 0.56$; 0.60/0.44). Direct emails (SC1.4.2) received a similar EoS score from analyst (0.63 on tablets and smartphones) and consumer managers (0.67 on both devices). Private emails (SC1.7.1) are relevant for analyst managers (0.38; 0.31). Private apps (SC1.7.2) are somewhat satisfying to them $(0.33 ; 0.36)$. Consumer managers are indifferent (0.11). Instant messaging (SC1.5.4) or other users' location (SC1.2.3) do not play a role $(0.25 / 0.07 ; 0.13 / 0.0)$.

Strongest differentiators for manager collaboration: Offer collaboration bars and push notifications on changes to shared office documents for analyst managers. Get consumer managers "online" with news tickers.

(2) Corporate management: Analyst managers evaluated monthly (financial) reporting (SC2.1), management dashboards (SC2.2) as well as filters (SC2.3.1) as must-be components. Consumer managers, in turn, ranked management dashboards as a must-be on both devices. Filters are considered attractive by consumer managers on both devices $(0.67 ; 0.56)$. Drill-downs (SC2.3.2) are evaluated by both manager types as satisfying on tablets and smartphones (analysts: 0.38 and 0.31 ; consumers: 0.44 on both devices). Creating own reports (SC2.3.3) is only satisfying to some degree for analyst managers on tablets (0.31), but not for consumer managers $(0.13 ; 0.00)$. Finally, a news ticker (SC2.4) is very satisfying for analyst and consumer managers on tablets $(0.63 ; 0.63)$ as well as on smartphones $(0.69 ; 0.63)$.

Strongest differentiators for corporate management: Make core reports more interactive with drill downs and filters for manager self-service.

(3) Mobile business life: Analyst and consumer managers highlight the need for flights and trains apps (SC3.2.1) on tablets and smartphones as must-be apps. A taxi app (SC3.2.2) was evaluated as more satisfying by analyst $(0.38 ; 0.44)$ than consumer managers $(0.33 ; 0.33)$. The former evaluates a web browser (SC3.1.2) as a must-be app and a search engine (SC3.1.1) as satisfying $(0.38 ; 0.38)$ becoming a must-be app (Figure 3). Consumer managers rated this app as satisfying to some degree (0.33; 0.33). In turn, business journal (SC3.4.2, $0.94 ; 0.63)$ and newspaper readers (SC3.4.1, 0.63; 0.44) are very attractive for analyst managers. The same rating applies to consumer managers on tablets $(0.89 ; 0.78)$. Convenience apps promise further benefits. 
A weather forecast (SC3.5.1, analyst managers: 0.63 on both devices; consumer managers: 0.56) or a restaurant finder (SC3.5.2, 0.50; 0.44) were evaluated by both manager types as equally attractive on both devices.

Strongest differentiators for mobile business life: Take "fun and enjoyment" into account when accommodating managers' business life.

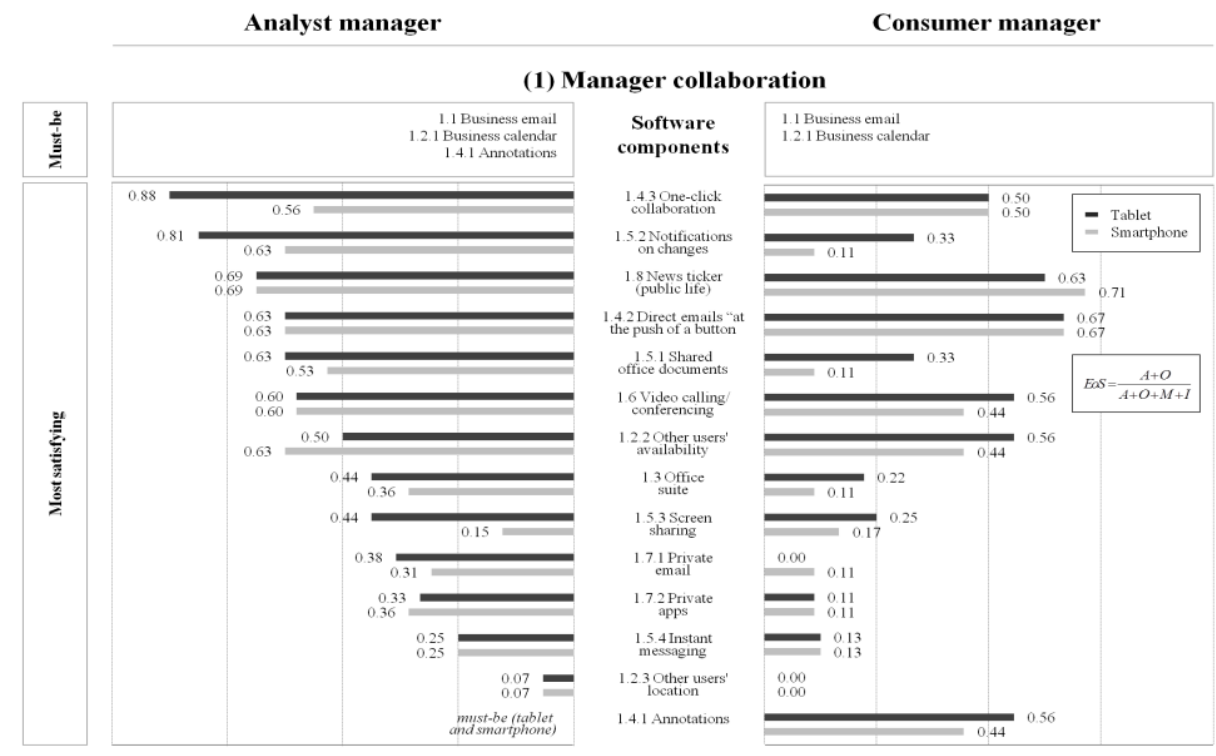

(2) Corporate management

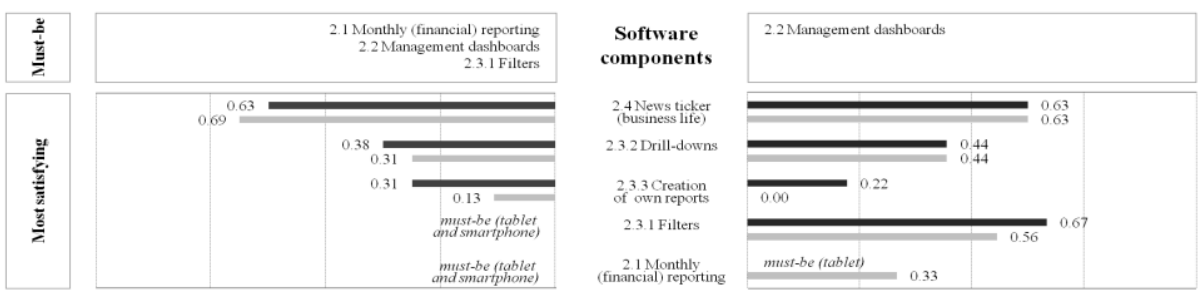

(3) Mobile business life

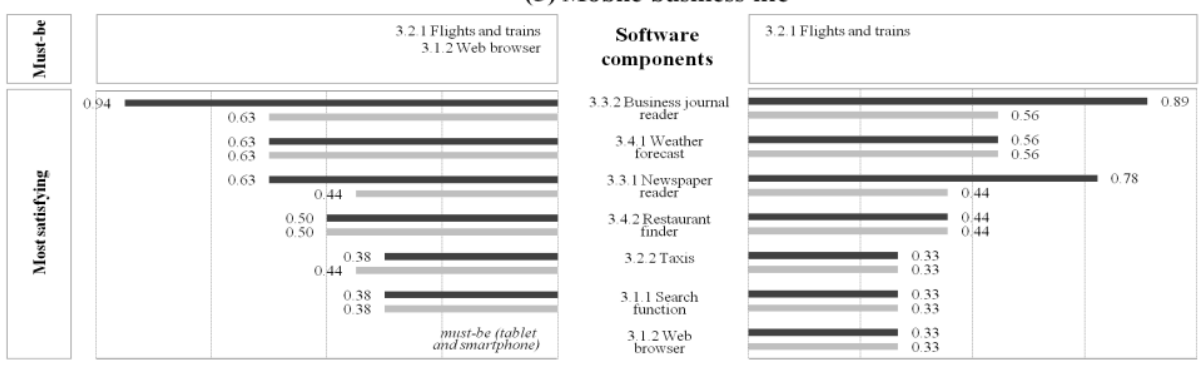

Figure 2. Results of the structured interviews

(4) Device selection: Eight apps such as video calling/conferencing or business journal readers received higher EoS scores on tablets than on smartphones. The reverse occurred three times for analyst managers and twice for consumer managers (e.g., news ticker for public life). Analyst managers argue that they are more satisfied with tablets than smartphones, because they can use them for sharing office documents simple ad-hoc analyses (create your own reports, SC2.3.3). Consumer managers can start using the app portal on a tablet, especially reading electronic newspapers. Some consumer managers would even use their smartphone instead of a tablet. However, from our interviews, managers do not feel comfortable with smartphones larger than 5 inches. 
Strongest differentiators for device selection: Consider that tablets create their own manager use case as their "first-stop information shop."

\section{Tablet}

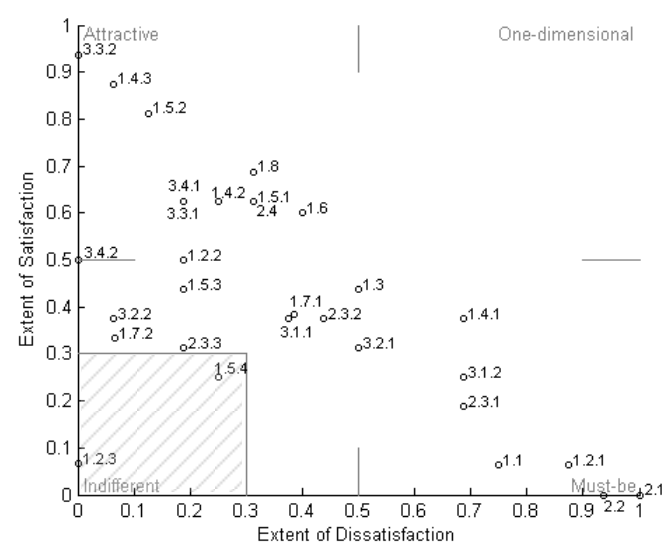

Smartphone

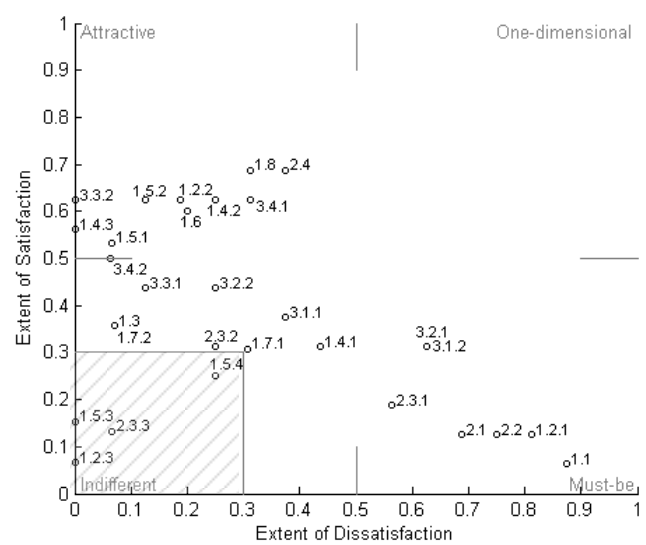

Figure 3. Representation of the results along EoS and EoD for analyst managers

\section{SYNTHESIS}

We discussed our results in January 2018 with two companies improving their manager IS support. Interviews were conducted with the head of management accounting (report provider) and a divisional head (recipient) of a chemical company (sales: 50 bn. EUR) and a divisional head of an automotive supplier ( $30 \mathrm{bn}$. EUR).

Based on the results from the Kano model (Figure 2 and 3), differences between analyst and consumer managers were clearly found. Thus, we propose the development of a basic manager app portal for consumer managers, which can be adapted to the more individual analyst manager. Both manager app portal designs incorporate the constitutive app cluster "corporate management" in the middle and the complementary clusters "manager collaboration" and "mobile business life" to the left and right of it (Krönke et al., 2017).

The top row covers a news ticker, a weather app, and search engine. There are the must-be apps like business email and calendar as well as travel apps. This extends to integrating document sharing and notifications on changes. However, the app portal designs for analyst and consumer managers have three differences: (1) Consumer managers evaluated neither screen sharing nor an office suite as must-be or attractive apps. Thus, these apps have been omitted. (2) In additional to filters and drill downs, the analyst manager app portal supports the creation of own reports. (3) The analyst manager app portal includes private apps (Figure 4).

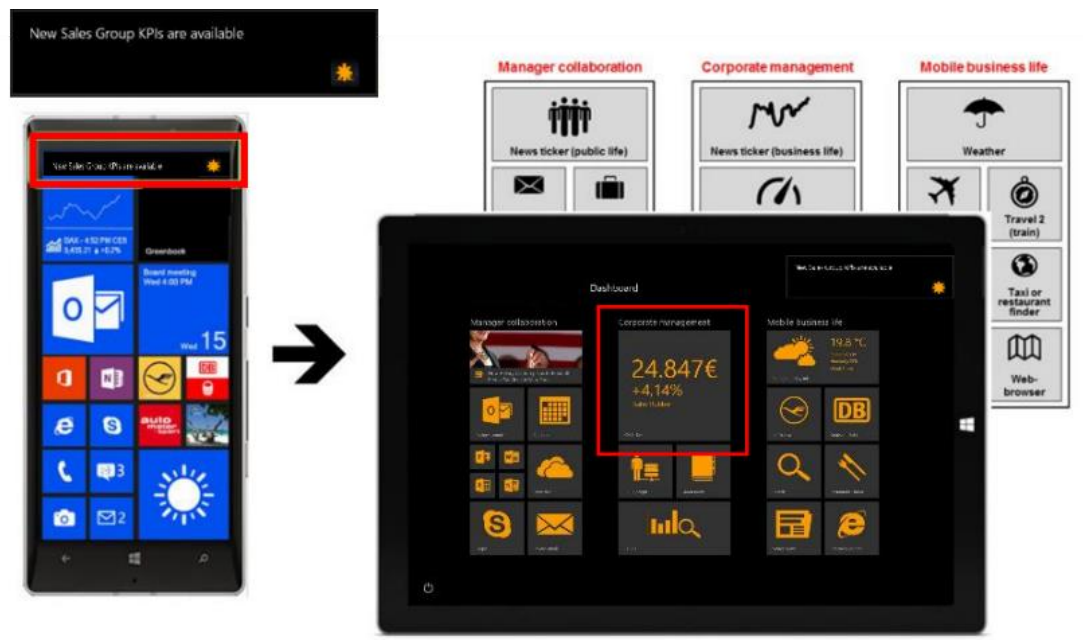

Figure 4. Analyst manager app portal on a tablet with a smartphone push functionality (Krönke et al., 2017) 
Several comments by the interviewed managers highlighted efficiency when mobile, e.g., "Draw my attention to critical events and I will be happy. I don't want to be bombarded with notifications every minute." The divisional head of the automotive supplier asked for a web browser: "I want to be able to check things on the internet," whereas his counterpart was less enthusiastic about restaurant finders and point-of-interest maps: "It is easier to ask the concierge."

Looking forward, remarks about intelligent automation were made such as filtering news relevant to the current travel destination(s) or an intelligent push of emails to the mobile device. Overall, the managers concluded that the "right" mix of apps will make the difference. Finally, all managers stated that our portal design would embrace manager self-service. The head of management accounting stated, "That is what is on my mind, when I think about manager self-service. However, for security reasons we will only allow choosing apps from a company pool."

\section{CONCLUSION}

The objective of this article was to examine which apps disproportionately influence managers' perception of IS usefulness. We propose a user-driven manager app portal design. We highlighted differences between "analyst-" and "consumer-type" managers. For practice, our findings can serve as a reference for both improving existing designs and future IS designs. For research purposes, the Kano model is an alternative starting point for investigations, not only for portal designs, but also for other kinds of IS in general.

Due to the number of apps the Kano model was best suited to our research. Although we introduced the Kano model to the interviewees, participants' understanding of the dysfunctional questions remains questionable. Future research should ensure that managers understand the Kano model more thoroughly, and, thus, provide more consistent answers. Hauser (1993) stated that 20-30 Kano interviews determine about $90-95 \%$ of all possible requirements. Our investigations were conducted with 25 individuals from eight different companies. Cheng et al. (2016) conducted a study with 22 participants. Our final number of interviews seems reasonable because of two reasons. Firstly, we interviewed experienced managers providing substantiated answers and secondly motivating this special kind of professionals to participate in surveys is difficult.

Another limitation is our number of IS use factors. Age, gender, education, IS experience, and working styles were not examined, which should be addressed in future work. Incorporating latest research on the Kano model (Madzík, 2018) might increase the quality of results further. Finally, examining the growing importance of fun and enjoyment when using IS is another avenue for research.

\section{REFERENCES}

Al-Kassab, J. et al., 2014. Information visualization to support management decisions. In International Journal of Information Technology \& Decision Making, Vol. 13, No. 2, pp. 407-428.

Alvarado, B. et al., 2011. Managing user-to-user contact with inferred presence information. Google Patents.

Belkadi, F. et al., 2013. A situation model to support awareness in collaborative design. In International Journal of Human-Computer Studies, Vol. 71, No. 1, pp. 110-129.

Benbasat, I. and Nault, B.R. 1990. An Evaluation of Empirical Research in Managerial Support Systems. In Decision Support Systems, Vol. 6, No. 3, pp. 203-226.

Bergeron, F. et al., 1995. Determinants of EIS use: Testing a behavioral model. In Decision Support Systems, Vol. 14, No. 2, pp. 131-146.

Carlsson, S.A. et al., 2009. An approach for designing MSS: the design science research process and its outcomes. Proceedings of the 4th International Conference on Design Science Research in Information Systems and Technology. Philadelphia, USA, pp. 1-11.

Chen, L.-S. et al., 2010. C-Kano model: a novel approach for discovering attractive quality elements. In Total Quality Management, Vol. 21, No. 11, pp. 1189-1214

Cheng, J. et al., 2016. Using the Kano Model to Balance Delight and Frustration for an Enterprise Application. Proceedings of the 2016 CHI Conference Extended Abstracts on Human Factors in Computing Systems. San Jose California, USA, pp. 3021-3027. 
Cronbach, L.J., 1951. Coefficient alpha and the internal structure of tests. In Psychometrika, Vol. 16, No. 3, pp. 297-334.

Fteimi N., 2017. A Taxonomy of IS Projects' Knowledge-sharing Mechanism. In Communications of the Association for Information Systems, Vol. 41 No. 26, pp. 611-638.

Gartner, 2018. Gartner Says By 2018, More Than 50 Percent of Users Will Use a Tablet or Smartphone First for All Online Activities. Available at: https://www.gartner.com/en/newsroom/press-releases/2014-12-08-gartner-says-by-2018more-than-50-percent-of-users-will-use-a-tablet-or-smartphone-first-for-all-online-activities [Accessed: 16 Jan. 2020].

Goodhue, D.L. and Thompson, R.L., 1995. Task-technology fit and individual performance. In MIS Quarterly, Vol. 19, No. 2, pp. 213-236.

Hauser, J.R., 1993. How Puritan-Bennett used the house of quality. In Sloan Management Review, Vol. 34, Spring, pp. 61-70.

Heineman, G.T. and Councill, W.T., 2001. Component-Based Software Engineering: Putting the Pieces Together. Pearson Education, Addison-Wesley, UK.

Herskovic, V. et al., 2011. The iceberg effect: Behind the user interface of mobile collaborative systems. In Journal of Universal Computer Science, Vol. 17, No. 2, pp. 183-202.

Herzberg, F. et al.,1959. The Motivation to Work. John Wiley, New York.

Hess, T. et al., 2014. Digital Life as a Topic of Business and Information Systems Engineering? In Business \& Information Systems Engineering, Vol. 6, No. 4, pp. 247-253.

Huysmans, J.H. 1970. The Effectiveness of the Cognitive-Style Constraint in Implementing Operations Research Proposals. In Management Science, Vol. 17, No. 1, pp. 92-104.

Kaneshige, T., 2011. 15 Best iPhone Apps for busy CEOs. Available at: https://www.networkworld.com/article/283 8481/15-best-iphone-apps-for-busy-ceos.html [Accessed 16 Jan. 2020].

Kettinger, W.J. and Marchand, D.A., 2011. Information management practices (IMP) from the senior manager's perspective: An investigation of the IMP construct and its measurement. In Information Systems Journal, Vol. 21, No. 5, pp. 385-406.

Kim H. et al., 2018. Unpacking organizational awareness: scale development and empirical examinations in the context of distributed knowledge sharing. In Journal of Applied Communication Research, Vol. 47, No. 1, pp. 47-68.

Krönke, B. et al., 2017. Manager App Portal at Continental: A Content, Collaboration, and Convenience App Selection That Works. In CONTROLLING - Zeitschrift für erfolgsorientierte Unternehmenssteuerung, Vol. 29, No 5, pp. 36-45.

Laudon, K.C. and Laudon, J.P., 2018. MIS: managing the digital firm. Pearson, Harlow, UK.

Lee, C.-P., Shim, J., 2006. An empirical study on user satisfaction with mobile business applications use and hedonism. In Journal of Information Technology Theory and Application (JITTA), Vol. 8, No. 3, pp. 57-74.

Lee-Partridge, J.E. and Snyder, J., 2012. Using the Layered Model to Understand Employee Selection of Information and Communication Channels for Information and Knowledge Sharing in Project Teams. Proceedings of the Conference on Information Systems Applied Research, San Antonio, USA, pp. 1508.

Luor, T. et al., 2015. Contribution to quality research: a literature review of Kano's model from 1998 to 2012. In Total Quality Management \& Business Excellence, Vol. 26, No. 3-4, pp. 234-247.

Madzík, P., 2018. Increasing accuracy of the Kano model - a case study. In Total Quality Management \& Business Excellence, Vol. 29, No. 3-4, pp. 387-409.

March, S.T., Smith, G.F., 1995. Design and Natural Science Research on Information Technology. In Decision Support Systems, Vol. 15, No. 4, pp. 251-266.

Matzler, K. and Hinterhuber, H.H. 1998. How to make product development projects more successful by integrating Kano's model of customer satisfaction into quality function deployment. In Technovation, Vol. 18, No. 1, pp. 25-38.

Neyem, A. et al., 2012. A reusable structural design for mobile collaborative applications. In Journal of Systems and Software, Vol. 85, No. 3, pp. 511-524.

Ostrov, P., 2014. Sales Analytics: Data Driven Forecasting for Better Quota Attainment. Available at: https://www. Aberdeen.com/cmo-essentials/sales-analytics-data-driven-forecasting-for-better-quota-attainment-2 [Accessed: 16 Jan. 2020].

Papageorgiou, E., De Bruyn, H., 2010: Creating Strategic Value Through Executive Information Systems: An Exploratory Study. Proceedings of the 3rd European Conference on Information Management and Evaluation, Gothenburg, Gothenburg, Sweden, pp. 380-399.

Powell, P.L. and Johnson, J., 1995. Gender and DSS Design: The Research Implications. In Decision Support Systems, Vol. 14, No. 1, pp. 27-58.

Riemer, K., et al., 2009. eCollaboration: On the nature and emergence of communication and collaboration technologies. In Electronic Markets, Vol. 19, No. 4, pp. 181-188.

SAP, 2019. Reimagine the SAP user experience with SAP FIORI. Available at: https://www.sap.com/products/fiori. html [Accessed: 8 Aug. 2019] 
Shneiderman, B., 1997. A grander goal: A thousand-fold increase in human capabilities. In Educom Review, Vol. 32, No. 6, pp. 4-10.

Sommerville, I.: Software Engineering. Pearson, München (2010)

Turban, E. et al., 2013.: IT for management: Advancing sustainable, profitable business growth. Hoboken. NJ: Wiley (2013)

Volonino, L. et al., 1995. Using EIS to respond to dynamic business conditions. In Decision Support Systems. Vol. 14, No. 2, pp. 105-116.

Walls, J.G. et al., 1992. Building an Information System Design Theory for Vigilant EIS. In Information Systems Research, Vol. 3, No. 4, pp. 36-59.

Wang W., and Reani M., 2017. The rise of mobile computing for Group DSS: A comparative evaluation of mobile and desktop. In International Journal of Human-Computer Studies, Vol .104, August 2017, pp. 16-36.

Watson, H.J. and Frolick, M.N. 2006. Determining information requirements for an EIS. In MIS Quarterly, Vol. 17, No. 3, pp. 255-269.

Willcocks, L. et al., 2008. The Ranking of Top IS Journals: A Perspective from the London School of Economics. In European Journal of Information Systems, Vol. 17, No. 2, pp. 163-168.

Wired, 2010. Apple Registers Trademark for "There's an app for that". Available at: https://www.wired.com/2010/10/appfor-that [Accessed: 16 Jan. 2020].

Witkin, H.A. et al., 1977. Field-Dependent and Field-Independent Cognitive Styles and Their Educational Implications. In Review of Educational Research, Vol.47 No. 1, pp. 1-64.

Wixom, B.H. and Watson, H.J., 2010. The BI-Based Organization. In International Journal of Business Intelligence Research, Vol. 1, No. 1, pp. 13-28.

Wu, C.-S., et al., 2011. User Acceptance of Wireless Technology in Organizations: A Comparison of Alternative Models. In Computer Standards \& Interfaces, Vol.33, No. 1, pp. 50-58.

Zhang, P. et al., 2002.: AMCIS 2002 Panels and Workshops I: HCI Research in the MIS Discipline. In Communications of the Association for Information Systems, 9, pp. 334-355.

Zigurs, I. and Buckland, B.K., 1998. A theory of task/technology fit and group support systems effectiveness. In MIS Quarterly, Vol. 22, No. 2, pp. 313-334. 